\title{
TARAPACA: APORTES A LA HISTORIA ANDINA DESDE UNA PERSPECTIVA REGIONAL (s. XV-XVI)
}

\author{
Simón Urbina Araya ${ }^{\mathrm{a}}$ y Mauricio Uribe Rodríguez ${ }^{\mathrm{b}}$
}

\begin{abstract}
Resumen
Se presenta un estudio de las formas sociopoliticas indígenas de Tarapacá mediante un enfoque histórico y arqueológico para el siglo XV y XVI. Se sistematiza la información correspondiente a los habitantes que residian en forma permanente o estacional entre la franja litoral del océano Pacifico, entre el rio Loa y Camarones, un extenso territorio colindante con los cacicazgos de Tacna al norte y las provincias incaicas de Atacama al sur, Caranga y Quillacas, al este. El análisis cualitativo de la información local y regional permite avanzar en la lectura de los datos arqueológicos y documentales, sugiriendo que durante la primera mitad del siglo XVI se habría desplegado una organización geopolitica caracterizada por la dinámica segmentaria de las poblaciones tarapaqueñas y el aparato provincial cuzqueño. Este trabajo propone que los españoles, al momento de la invasión, pudieron observar en esta región el funcionamiento de las jurisdicciones incaicas o wamani, a partir de lo cual se deberian analizar las posteriores transformaciones coloniales ocurridas dentro del virreinato peruano.
\end{abstract}

Palabras clave: virreinato del Perú, historia andina, Periodo Inca-Colonial, Tarapacá

\section{Abstract}

\section{TARAPACA: CONTRIBUTIONS TO ANDEAN HISTORY FROM A REGIONAL PERSPECTIVE}

Through both an archaeological and historical approach, we present a study of the indigenous sociopolitical formations of the Tarapaca region for the 15th and 16th centuries. Information is systematized from early documentary sources related to the permanent and seasonal populations residing along the Pacific coast between the Loa and Camarones rivers, an area bordered by the chiefdoms of Tacna and the Inca provinces of Atacama, Caranga, and Quillaca. Our qualitative analysis of regional and local historical and archaeological sources from the beginnings of the Spanish colonial period (1535-1571), suggest that regional geopolitical organization was characterized by the fragmentary dynamics among the Tarapacan populations and the provincial Inca apparatus. The available data suggest that at the time of the Spanish conquest of the Tarapaca region, the establishment of a cultural hierarchy and local and regional political affliation were linked to the operation of an Inca provincial jurisdiction (or wamani).

Keywords: viceroyalty of Peru, Andean history, Inca-colonial Period, Tarapacá

${ }^{a}$ Laboratorio de Arqueología, Dirección Museológica, Universidad Austral de Chile

Correo electrónico: simon.urbina@uach.cl

b Departamento de Antropología, Facultad de Ciencias Sociales, Universidad de Chile

Correo electrónico: mur@uchile.cl 


\section{Introducción}

La comprensión de los períodos Tardío y Colonial en la región de Tarapacá (ca. $19^{\circ}-21^{\circ}$ Lat. S), en el actual norte de Chile, se ha mantenido subordinada a la investigación arqueológica e histórica efectuada mayormente hace tres décadas atrás. La carencia generalizada de nuevas fuentes documentales (Pärssinen 2002[1993]: 10 y 31) y el uso acrítico de aquellas que tratan el epílogo de la época incaica e inicios del sistema de encomienda (v.g. Cúneo-Vidal 2004[1977]), han impedido avanzar y discutir los datos generados por la arqueología de los Andes Centro Sur (Núnez 1984, t. II: 409-422) (Fig. 1).

El presente trabajo busca responder a la necesidad de contar con una primera sistematización etnohistórica del período de invasión hispana y declinación del Tawantinsuyo en la región para comprender de mejor modo el registro arqueológico de los siglos XV-XVIII (Urbina 2010; Uribe y Urbina 2010; Zori 2011; Uribe et al. 2012). La información recopilada sugiere elementos políticos y componentes culturales omitidos o desestimados por la investigación regional sobre las diversas poblaciones de Tarapacá ${ }^{1}$ que formaban parte del Tawantinsuyo. De este modo, intentaremos verificar y dotar de contenido la hipótesis según la cual mediante la construcción de una instalación urbana (sensu Hyslop 1984: 277, 1990) en las tierras bajas (yunga) de la región —el pueblo de Tarapacá o Tarapacá Viejo-, el Tawantinsuyo habría consumado en etapas, mediante negociación y/o coerción político-militar, la intervención de una red ecológicamente dispersa de jerarquías inclusivas radicadas en asentamientos de distinta envergadura dentro de la región de Tarapacá.

En términos metodológicos, nos basamos en el análisis del patrón de asentamiento regional (Adán y Urbina 2010) y los antecedentes que sobre esta variable puede derivarse a partir de un análisis sintáctico de la información histórica contenida en fuentes secundarias o publicadas. El planteamiento tiene un énfasis en la situación y transformaciones geopolíticas que documentan los asentamientos tarapaqueños a partir de la expansión y presencia del Tawantinsuyo (ca. 1400-1535/1540) y la etapa de invasión hispana (ca. 1535-1571), en relación con sus habitantes y autoridades vigentes en cada época. Con todas las precauciones que significa esta mirada retrospectiva, nuestro trabajo está dirigido a documentar la definición geopolítica de Tarapacá antes de la década de 1570, lo cual nos parece fundamental para evaluar las investigaciones que han tratado la implantación de las encomiendas, los pueblos o reducciones de indios, la conformación de las doctrinas, la estructura parroquial, así como en general las consecuencias de las políticas toledanas en la región ${ }^{2}$.

\section{La denominación y el topónimo Tarapacá}

Según la primera terminología, Tarapaca correspondería al espacio entre el río Loa y la quebrada de Camarones (Sanhueza 2008: 60) e inclusive, un territorio algo más vasto entre el río Loa y «.... el sur del río Lluta» (Wachtel 2001[1990]: 565). A mediados del siglo XVI, la voz Tarapaca designaba el valle norte-sur conocido como Pampa del Tamarugal, el cual se extiende entre el río Loa y la quebrada de Tiliviche (Advis 2008: 38-40). Tarapacá corresponde, dependiendo del contexto, a una unidad geo morfológica, un curacazgo étnico o una provincia Inca aún mayor, limitante al norte con la quebrada de Camarones (Advis 2008: 168) o inclusive Codpa, lugar este último, parte de la jurisdicción de los cacicazgos de Tacna (Hidalgo 1986: 20-21).

Desde cierto punto de vista, la crónica de la expedición de Almagro en 1537, es la primera fuente en registrar el nombre de Tarapaca asociado a una gran unidad orográfica y jurisdiccional. Los testimonios indican que la hueste de Almagro ingresó a Tarapaca a fines de 1536, indicándola como "... otra provincia» (Fernández de Oviedo 1901[1557]: 250). Vivar (1979[1558]: 11-13), junto a Pedro de Valdivia, indica que la provincia se ubicaba a 37 leguas adelante por «un camino" originado en la provincia de Tacna, con los «... ríos que proceden de las sierras y cordillera nevada [...] en estos valles no llueve las quince y dieciséis leguas $[ \pm 100 \mathrm{~km}, \mathrm{E}-\mathrm{O}]$ que digo que hay de cordillera nevada hasta la mar». Por otra parte, Pedro Sande informa al factor de Potosí 


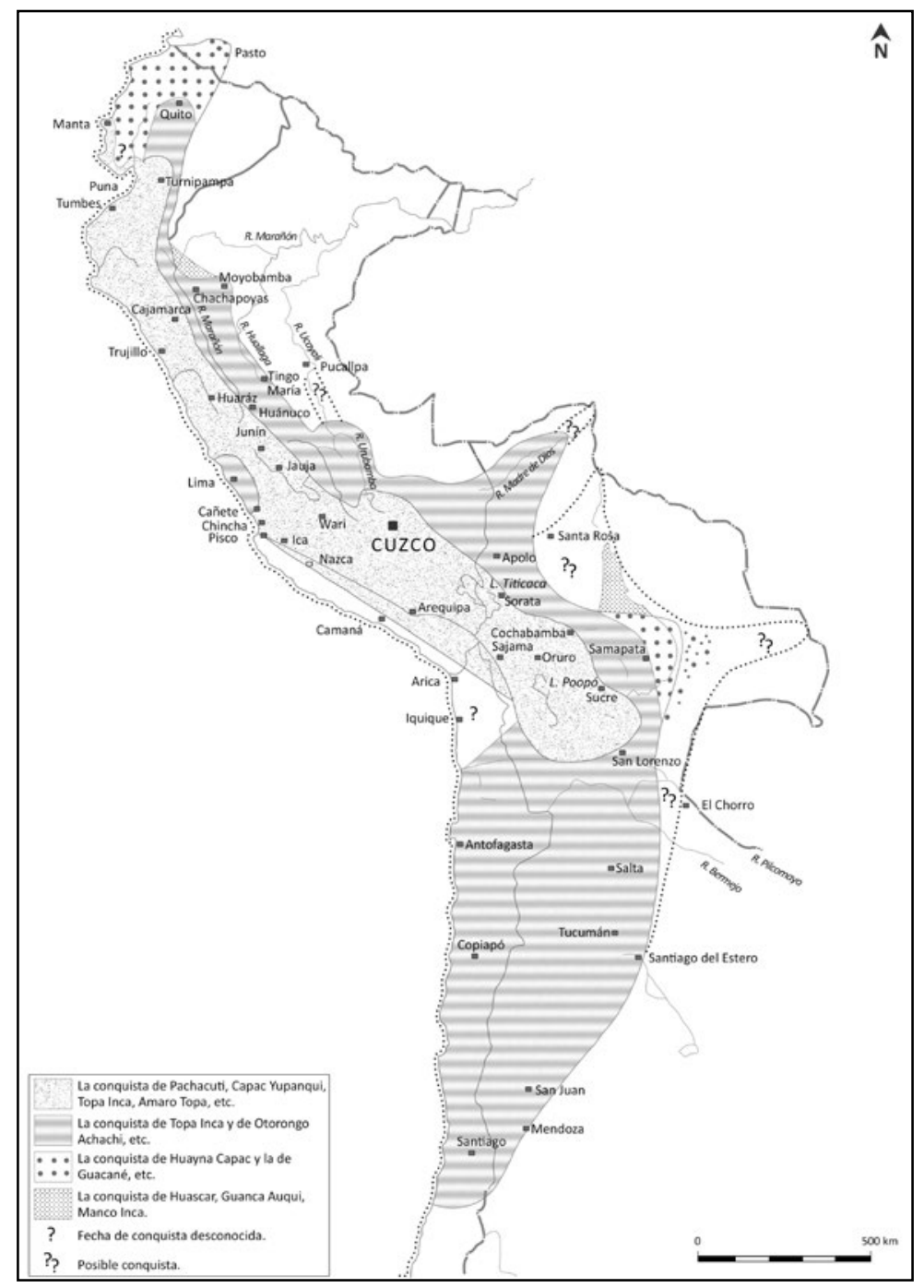

Figura 1. Esquema de la expansión incaica. Modificado de Parsinnen (2002[1993], mapa 11: 128). La flecha en negro indica la ubicación de Tarapacá. El signo de interrogación refiere a una "fecha desconocida de conquista".

(Lozano de Machuca 1992[1581]: 32) que la costa del distrito de Tarapacá incluía «... desde el puerto de Pisagua y Hiquehique (...) hasta el puerto del Loa».

De esta manera, el valle de Tarapaca comprendía bajo la mirada hispana toda la depresión de la Pampa del Tamarugal entre la quebrada de Tana y el río Loa ( $\pm 350 \mathrm{~km}, \mathrm{~N}-S$; Fig. 2), la cubierta de bosques y el tramo bajo de la actual quebrada de Tarapacá, «... como unidad» (Advis 1989; Núñez 1984, t. II: 413). Tal denominación no era homóloga a la denominación «quebrada de Tarapacá» o «valle de Cato» en el siglo XVI (Odone 1994: 40-41; Barriga 1955). Sin embargo, Pedro Pizarro (1986[1571]: 189-192) señala que las minas de Tarapaca [luego Huantajaya] «... tienen ese nombre por un pueblo que se encuentra a nueve leguas de estas minas», lo cual extiende el uso del topónimo al pueblo de Tarapaca y a los minerales de plata ubicados en la cordillera de la Costa, es decir a ambos costados de la Pampa del Tamarugal o «valle de Tarapaca» (subrayados nuestros).

El segundo aspecto geopolítico importante de distinguir es el significado etnográfico del término presente desde la incursión de Diego de Almagro, por cuanto la señala como «la primera del Collao» 
viniendo desde el sur, a la «provincia de Tarapaca» (Fernández de Oviedo 1901[1557]: 251). ¿Se trata de una alusión a la división administrativa del, en ese entonces, declinante Tawantinsuyo? En la comitiva de Almagro viajaba con un numeroso destacamento incaico encabezado por Paullo Tupac, hijo de Huayna Capac, además de «3000 indios cuzcos» bajo las ordenes de sus propios capitanes (Advis 2008: 184). Por esta razón debiera evaluarse si las primeras menciones de Tarapacá, transcritas por Fernández de Oviedo fueron obtenidas de una fuente cuzqueña de alto rango o un informante hispano.

El Collasuyo, como es sabido, involucraba las poblaciones ubicadas desde el suroeste del Cuzco, pasando por la cuenca del lago Titicaca y su prolongación hacia el altiplano meridional de Bolivia, noroeste y centro oeste argentino, hasta el centro de Chile (D’Altroy 2002: 306-308). Una postura algo distinta mantiene María Rostworowski (1986: 127), basándose en las Memorias de las iglesias, curatos, doctrinas y monasterios del Obispado del Cusco (1584). Allí se menciona que desde el valle de Tarapacá hasta Camaná, al norte de Arequipa, una serie de cuencas ubicadas entre la Cordillera de los Andes y sus vertientes marítimas formaban parte de la provincia del Colesuyo, cuya «capital del Partido", estaba en Moquegua, según los Protocolos Notariales de 1596-1600 (Rostworowski 1986: 128).

Para Pärssinen (2002: 24) aún no es claro si Colesuyo refería originalmente a una gran confederación administrativa dentro del Collasuyo o del Contisuyo. En términos demarcatorios, si se considera la Instrucción de las doctrinas de los Obispados de la ciudad del Cuzco y la ciudad de La Plata, 1556-1561, el Contisuyo se componía de dos partes: el Condesuio, jurisdicción de la ciudad de Arequipa y "comienzo de la sierra»; y, en segundo lugar, el distrito de Arequipa agrupado bajo el título de Collesuio, el que «... parece haber pertenecido al Collasuyu» (Pärssinen 2002[1993]: 223). Pärssinen estima que el «Colesuyo fue una parte del Collasuyo [...] el texto del Capac Ayllu (1985[1569]: 226), derivado de un(os) khipu(s) incaico(s), menciona a Tarapacá como parte del Collasuyo" (2002, nota 4: 35; 2003[1992]: 224). Esta última mención apoya la impresión de Almagro cuando, al ingresar a Tarapacá desde el sur, anota estar en la primera provincia del Collao (Fernández de Oviedo 1901[1557]). Sin embargo, Osvaldo Silva, apoyándose en la definición de Cieza de León, estima que el Collasuyo limitaba al poniente con «... las cabezadas de las sierras nevadas y vertientes de ellas», por lo que «... Tarapaca se ubicaba en otra división geográfica-administrativa, el Colesuyo» (Cieza 1984[1553]: 442, en Silva 1992-1993: 86-87).

Una última información relevante al respecto, es aquella mencionada por Pizarro sobre las provincias "que en esta tierra hay», donde indica aquella que se extiende desde Tambo [Tacna] hasta Pica [sur de Tarapacá] (1986[1571]: 220). En esta referencia temprana, a pesar de las varias unidades políticas existentes (Martínez 2011: 111), el cronista reconoce una unidad administrativa mayor, la cual es probablemente asimilada por Pizarro a los suyos del imperio (Martínez 2011: 112). Hemos visto que esta relación entre Tacna y Tarapaca también se menciona previamente en la crónica del viaje de Almagro, al momento en que concertadamente se intenta detener el avance de la expedición.

La última mención relevante, refiere al topónimo Tarapaca o Tonapa (Santa Cruz Pachacuti 1993[1613]: 188, f. 3v), vocablo que en las crónicas coloniales refiere a una poderosa deidad cuya influencia religiosa conformaba, de igual modo, un extenso territorio sagrado. Históricamente este espacio liga varios mitos que narran el viaje civilizador del personaje, donde ocurren relaciones amorosas y luchas o disputas entre volcanes de importancia regional (v.g. Tunupa [Quillacas], Taapaca [Arica] o Sajama [Pacaje], entre otros), todos ellos ubicados alrededor de aquella área geográfica (de Tarapaca).

Según el estudio de María Rostworowski (1988), Tunupa o Taapaca fue una divinidad muy antigua extendida en los ámbitos costeros y serranos del actual sur de Perú, norte de Chile, Altiplano Circumtiticaca y Meridional de Bolivia. Posiblemente su área de influencia llegó a su máxima extensión antes del auge del culto a Viracocha, especialmente en el Colesuyo y la región altiplánica adyacente. Su territorio mítico involucraba las cuencas del lago Titicaca, río Desaguadero, el lago Poopó y las cuencas de los salares de Coipasa y Uyuni, de igual modo que los Valles Occidentales de Arica y Tarapacá. 
En suma, debe mantenerse la distinción entre al menos dos o tres conceptualizaciones del término Tarapaca, una de mayor contenido geográfico; otra más enfocada en su ubicación político administrativa desde una perspectiva local y otra incaica, también asociada a su importancia en la mito-historia andina. El estudio arqueológico e histórico de las poblaciones que habitaron dicho espacio durante los siglos XV y XVI, por lo tanto, debe considerar estos aspectos en forma combinada; el extenso territorio que abarca $( \pm 40.000 \mathrm{~km} 2)$ la región con sus diversas connotaciones culturales, étnicas y económicas.

\section{La población y sus asentamientos}

Los documentos hispanos entregan valiosa información sobre la población nativa de Tarapacá y sus asentamientos a partir de las expediciones de Almagro en 1536 (Fernández de Oviedo 1901[1557]) y Pedro de Valdivia entre 1537-1540 (Rojas-Mix 1991; Vivar 1979[1556]), junto con otras fuentes, algo más tardías.

En su paso por la sección media del río Loa, siguiendo de la localidad de Chiu Chiu al río Chunchor y luego por la caja del Loa hasta Quillagua, según Cúneo (1977, v. 10: 337), la comitiva de Almagro habría topado con los quillaguas. Lamentablemente, el historiador no cita las fuentes que utiliza en este extenso trabajo ${ }^{3}$. Quillagua constituía un oasis del "valle de Tarapaca» desde el siglo X, al menos, un espacio fluvial y de vegetación articulador en medio del desierto, por tal razón, no carente de tensiones entre del sur de Tarapacá. En su estudio de la variabilidad textil en los cementerios del valle de Quillagua, Agüero y colaboradores (1997: 263-290) indican que esta localidad habría sido escenario de una constante interacción entre poblaciones atacameñas y de Tarapacá durante los siglos X y XV. El vestuario en Quillagua habría funcionado como un «... instrumento de dialogo, que admitió y negoció las diferencias, sin la necesidad de violencia física (...) introdujo, elementos formales y decorativos del estilo tarapaqueño, sobre un sustrato estructural del estilo de Atacama» (Agüero et al. 1997: 286).

En el siglo XVI, bajo un clima de resistencia a la invasión hispana, entre los oasis Quillagua y Pica, Paullo Tupac habría ordenado a las autoridades indígenas de las «provincias» de Tarapacá y Tacna enviar guerreros a las costas, bajo la sospecha que Almagro efectuaría un viaje en barco por el litoral. Sobre el mismo punto, y refiriendo al parecer a una autoridad Inca provincial, no a Paullo Tupac, Advis (2008: 149-150) destaca que en el litoral Pacífico del extremo sur del Perú y Norte de Chile «... el cacique Inga proveyó de gente en todos los puertos para que le matasen al general e a los que con él viniesen» (Fernández de Oviedo 1901[1557]: 250, subrayado nuestro). La mención a este cacique incaico con jurisdicción sobre la región tacneńa y tarapaqueńa es de relevancia, no sólo por la data del informe, sino porque alude a la actuación de una autoridad provincial o Tocricoc (Pärssinen 2002[1993]: 239-241) e, inclusive, de mayor jerarquía inter provincial como el cargo de Suyoyoc Apo (Pärssinen 2002: 33-34). Por ello, según se indicó previamente, es muy probable que el funcionamiento concertado de poblaciones de tarapaqueñas y tacneñas sea más que sólo una respuesta contingente a la invasión europea (Pizarro 1986[1571]).

En Tacna, junto al valle de Caplina y Arica, así como Tarapacá, desde el río Camarones al Loa, cada vez con mayor fuerza los estudios demuestran la coexistencia de varios grupos étnicos (Silva 1992-1993: 89-91; Hidalgo 2004[1986]: 428; 2009: 158). Además, como ocurría en Arica, «... algunos grupos étnicos prehispánicos incluían en su seno más de una etnia» (Hidalgo 2004[1986]: 421). Idealmente, esta situación requería de una versátil intervención del Inca, o de autoridades provinciales designadas capaces de regular, mediar y monopolizar la dinámica vertical y horizontal de las relaciones políticas, económicas, parentesco o alianza y conflicto entre diversos grupos y sus dirigentes (Morris y Covey 2003:134).

De acuerdo con Barriga (1952, t. IV: 165), es probable que la principal área de asentamiento del oasis piqueño, al noreste del valle de Quillagua, se encuentre bajo el actual centro del pueblo, obliterado por la instalación de la actual iglesia de San Andrés y su explanada adyacente. Justamente, este lugar aparece mencionado como lugar de la primitiva «iglesia de indios» en 1578 (Advis 1995: 91). 
Según la lectura de las crónicas de Fernández de Oviedo y Vivar, Pica estaba conectada con la quebrada de Tarapacá $( \pm 65 \mathrm{~km}$ ) por varias postas de chasquis. Ambas localidades además exhiben una estrategia política concertada frente a la invasión, puesto que se señala que habían despoblado y ocultado sus bastimentos por igual (Fernández de Oviedo 1901[1557]: 250-251, en Advis 2008: 163). La quebrada de Tarapacá, la de mayor relevancia económica y cultural en la historia de la región (Núñez 1979, 1978), fue el siguiente lugar de arribo y estadía de Almagro.

Hasta el momento, las menciones más tempranas al «pueblo de Tarapacá» se encuentran en dos documentos (Advis 2008: 159). El primero es la Probanza de servicios de Diego de Encina (Barriga 1933: 272) y el segundo, en un legajo judicial de 1540 (Medina, CDI, t. V: 370) donde el adelantado al regreso de Chile «... viniendo por su camino con la prisa que podía, é llegado al pueblo de Tarapacá, que es en los términos e límites del Cuzco». Esta información puede entenderse de dos maneras; la primera referida a la incorporación de Tarapaca al Tawantinsuyo, aunque esto no implicaba todos los espacios, recursos y poblaciones que en ella residían en el siglo XV y XVI (Urbina 2009). Debido a que pudiera tratase de una mirada esencialmente cusqueña, transmitida por el contingente incaico de la expedición, es posible que esta descripción física política apuntara a mostrar dicho espacio como dependiente del imperio y sus administradores provinciales y no de sus autoridades locales u otras jurisdicciones étnicas menores ${ }^{4}$.

Al dejar Tarapacá — según informa uno de los capitanes de Pedro de Valdivia, Pedro de Villagra (Medina, CDI, t. XXIII: 61)—, Almagro debió tomar el camino de la cordillera de la costa, también llamada "sierra marítima», en dirección al puerto de Arica distante unos $\pm 200 \mathrm{~km}$ (Advis 2008: 164-165). Pedro de Valdivia siguiendo la dirección Tacna-Tarapacá habría estado informado de la ruta seguida por Almagro en su regreso al Cuzco, pues entre los 20 españoles que venían con Valdivia desde Arica estaba Pedro Gómez de don Benito, que ya había formado parte de la hueste de Almagro (de Ramón 1953: 109, en Advis 2008: 166).

La crónica de Jerónimo de Vivar refiere también a otra ruta inter provincial en sentido esteoeste, señalada como un "camino», la cual fue utilizada por los hispanos entre el valle de Tarapacá y Charcas; en "Arequipa... halló (Pedro de Valdivia) a su capitán Alonso de Monroy. Luego lo despachó para el Collao y que recogiese toda la gente que por allí se viese recogido para la jornada, y que llegase a Charcas con cierta cantidad de monedas para socorrer a los soldados que hallase en la villa de la Plata [Chuquisaca] y en Porco y con todos se viniese al valle de Tarapaca que es en el mismo camino que habían de llevar, treinta y siete leguas adelante del valle de Tacna» (Vivar 1979[1558]: 12, subrayados nuestros).

El cronista utiliza el topónimo valle de Tarapacá, como ocurre a partir de 1536, aludiendo a la unidad conformada por la pampa entre los ríos Camarones y Loa, la cordillera de la costa y varios valles endorreicos. También destaca que dicha "provincia» involucraba además de los ríos que bajan la cordillera, donde «... los naturales tienen abiertas muchas acequias de donde riegan sus sementeras», a partir de lo cual es inteligible su reseñada mención a «... Tarapacá, valle fértil de bastimento" (Vivar 1979[1558]: 12). Justamente, dentro de los espacios habitados y fértiles se encontraba aquel desde donde Pedro de Valdivia, luego de componer su hueste, «Salió [...] con su gente puesta en orden para el valle de Atacama que está a setenta leguas...». Esta distancia ( $\pm 390 \mathrm{~km}$ al sureste), a los oasis del Salar de Atacama, se ajusta a la idea de Advis (2008: 162-163) según la cual, Valdivia habría alojado en 1537 en un asentamiento de la «quebrada de Tarapacá», posiblemente Tarapacá Viejo (Fig. 2).

Dicha hipótesis parece ser confirmada por la relación de Pedro Pizarro (1986[1571]), donde anota que las minas de plata de Tarapacá «... tiene ese nombre de Tarapacá por un pueblo que ésta a doce leguas de esta mina (...) Lucas Martínez, vecino de Arequipa, uno de los conquistadores de este reino, labraba estas minas porque tenía en encomienda este pueblo de Tarapaca» (1986[1571]: 189 y 190). La distancia referida $( \pm 67 \mathrm{~km})$ coincide con aquella entre el cordón de Huntaca, en la cordillera de la Costa frente a Iquique, y el actual poblado de San Lorenzo de Tarapacá fundado en 1717 (Barriga 1952, t. IV: 162), ratificando que el «pueblo de Tarapacá» sería Tarapacá Viejo (Fig. 3), asentamiento inca-colonial ocupado entre los siglos XIV e inicios 


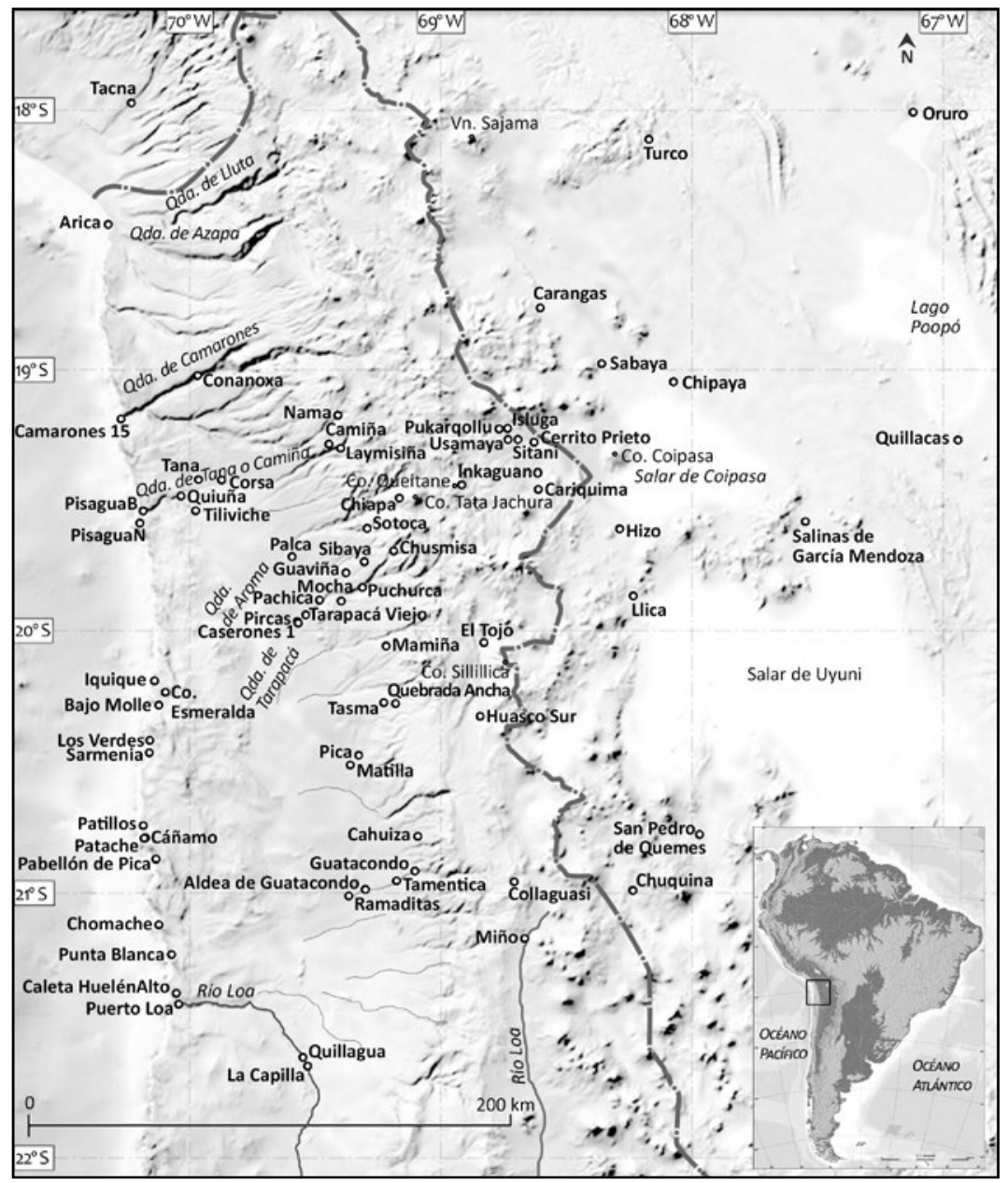

Figura 2. Región de Tarapacá con principales asentamientos mencionados en el texto.

del XVIII (Meza 1950: 32; Núñez 1978: 914-917; Villalobos 1979: 30-31; Núñez 1984: 62-64). Según Lockhart (1968: 56) y Núñez (1984, t. II: 416) dicho asentamiento aparecería mencionado durante el siglo XVI como el "tambo de Tarapacá», aunque ambos autores no especifican las fuentes utilizadas para sostener dicha denominación referida al sistema vial incaico.

Puesto que Vivar menciona el encuentro entre Francisco de Villagra, procedente de Tarija, y Pedro de Valdivia «... en un pueblo que se dice Los Capiruzones» (Vivar [1558] 1979: 13), Advis supone que tal asentamiento sería el "pueblo de Tarapacá» o Tarapacá Viejo debido a la omisión y falta de menciones en la documentación a los «indios de Tarapacá», habitantes la quebrada más importante de la región, o siquiera una parcialidad de esta (Advis 2008: 162-163). En segundo lugar, infiere que Valdivia — al igual que con Monrroy procedente desde Charcas—, esperó a Francisco de Villagra estacionado en la quebrada de Tarapacá.

Sin embargo, la crónica de Vivar señala que antes del encuentro «... salió el general de este valle de Tarapacá para el valle de Atacama» y, luego, que en el referido pueblo «... se le juntó Francisco de Villagra, proveniente de Tarija» (Vivar 1979[1558]: 13). De esta manera, a pesar de los indicios es imposible aún confirmar si Tarapacá Viejo corresponde al pueblo de «los caperuzones». Por el momento, este es el único cronista que menciona a "los caperuzones» y, más importante aún, Tarapacá Viejo es uno entre varios poblados aglutinados tardíos ubicados en el valle inferior 
de Tarapacá, entre Huarasiña y Pachica (Núñez 1978, fig. 1: 907, 911-915; 1979: 173-181; Zori 2011). Por último, puesto que la llegada de Valdivia fue comunicada a los indios de Atacama por aquellos que «... llaman caperuzones y de los de Guatacondor y de Pica» (Vivar 1979[1558]: 18), sus habitantes al parecer poseían asiento más cerca del río Loa que al norte de Pica.

Si se atiende al significado colonial del adjetivo, parece más fiable, que «caperuzones» refiera al atuendo textil o gorro indígena, cuyo distintivo era una caperuza o bonete ${ }^{5}$, el cual utilizaban los habitantes de un asentamiento ya reconocido por los españoles, rasgo que seguramente los diferenciaba en el siglo XVI, de aquellos de Pica y Guatacondo. Precisamente, de acuerdo a la información textil de sitios arqueológicos, los «caperuzones» corresponderían a los individuos con gorros con bonete o coleta, propios de contextos del período Intermedio Tardío (s. XIII-XV d.C.) en localidades atacameñas del Loa (Chiu Chiu y Chacance). Específicamente se reconocen estos elementos del atuendo en el cementerio Chacance-1 (Agüero 2007: 102-103), «... donde a diferencia de Chiu Chiu existe una situación de contacto entre las poblaciones de Atacama y Tarapacá».

De acuerdo a la formulación de Advis (2008), recientemente se han registrado diversos asentamientos aglutinados ubicadas en las quebradas de Tarapacá (Fig. 4), donde la arquitectura doméstica o las vías de circulación presentan sobre bloques rocosos representaciones rupestres (Figs. 5 y 6) «... bastante pautadas de la figura humana en Chusmiza y Jamajuga [las que] hacen referencia directa a la vestimenta y tocados usados por estas poblaciones asignadas al Complejo Pica-Tarapacá, y son vinculables a la evidencia textil de la zona como túnicas semi trapezoidales, cascos y gorros con coletas, objetos que se relacionan con situaciones de identidad e interacción con otras poblaciones» (Agüero 2007, fig. 17: 54 , fig. 29: 134; Vilches y Cabello 2011, fig. 6, C3 y C4: 45-46). En suma, con la evidencia disponible, «los caperuzones» corresponderían a poblaciones tarapaqueñas de tierras altas o habitantes de la cuenca del río Loa Medio, identificados por su vestimenta, tocado o gorro (Martínez 2011, fig. VI.1, VI.2 y VI.3: 218-219, Museo Chileno de Arte Precolombino 2015: 59-60, 67-71).

De cualquier modo, la percepción europea en el siglo XVI, a pesar de lo fugaz que puedan haber resultado las primeras expediciones, pudo referir a identidades dentro de un marco étnico compartido, aunque bastante heterogéneo. Como se indica hacia el final de este trabajo, prácticas co-residenciales documentadas entre grupos de quebradas (Tarapacá) y oasis (Pica) instalados en el litoral desértico entre Pisagua y el río Loa, aluden al modo tradicional de uso del espacio en Tarapacá a partir del siglo IX a.C. (Núñez 2006; Uribe 2009: 24). Las investigaciones señalan que justamente el Complejo Pica-Tarapacá (ca. 900-1450 d.C.) correspondía a sociedades segmentadas en parcialidades de distinto tamaño, residentes en oasis, quebrada aledañas a la Pampa del Tamarugal, costa Pacífico y sectores de tierras altas, las cuales compartían — durante los siglos previos a la invasión europea (s. X-XV d.C.) -, elementos de su cultura material tan significativos como la vajilla culinaria y ceremonial, sus atuendos textiles cotidianos, festivos y funerarios (Núñez 1984; Uribe 2006; Agüero 2007).

Caminos longitudinales por el valle eran atravesados por una densa red de caminos caravaneros y peatonales que unían los poblados del altiplano, las quebradas y valles bajos, mientras otros atravesaban la sierra marítima para acceder a localidades en la costa como caleta Camarones, Pisagua, Iquique, Cavancha, Los Verdes, Chucumata, Caramucho, Patache, Chomache, Chipana y el río Loa (Briones et al. 2005, fig. 1: 197, Berenguer et al. 2011; Urbina et al. 2011). En esta lista, uno de aquellos terminales costeros principales debió ser Iquique (Iqueyque), lugar donde la terraza marina formaba una pequeña península que se proyecta hacia el océano hasta una isla donde existía un gran depósito de guano fósil. Como indica Cieza de León «Más adelante están los ricos valles de Tarapacá. Cerca del mar, en la comarca de estos valles, hay unas islas bien pobladas de lobos marinos. Los naturales van a ellas en balsas, y de las rocas que están en sus altos traen gran cantidad de estiércol de las aves para sembrar sus maizales y mantenimientos" (Cieza 1967[1551]: cap. LXXV, citado en Chacón e Hidalgo 1983: 112, subrayado nuestro).

Durante tiempos coloniales tempranos el guano era explotado, con cierta especialización por grupos balseros del litoral y luego transportado hasta el interior para su uso como fertilizante en 


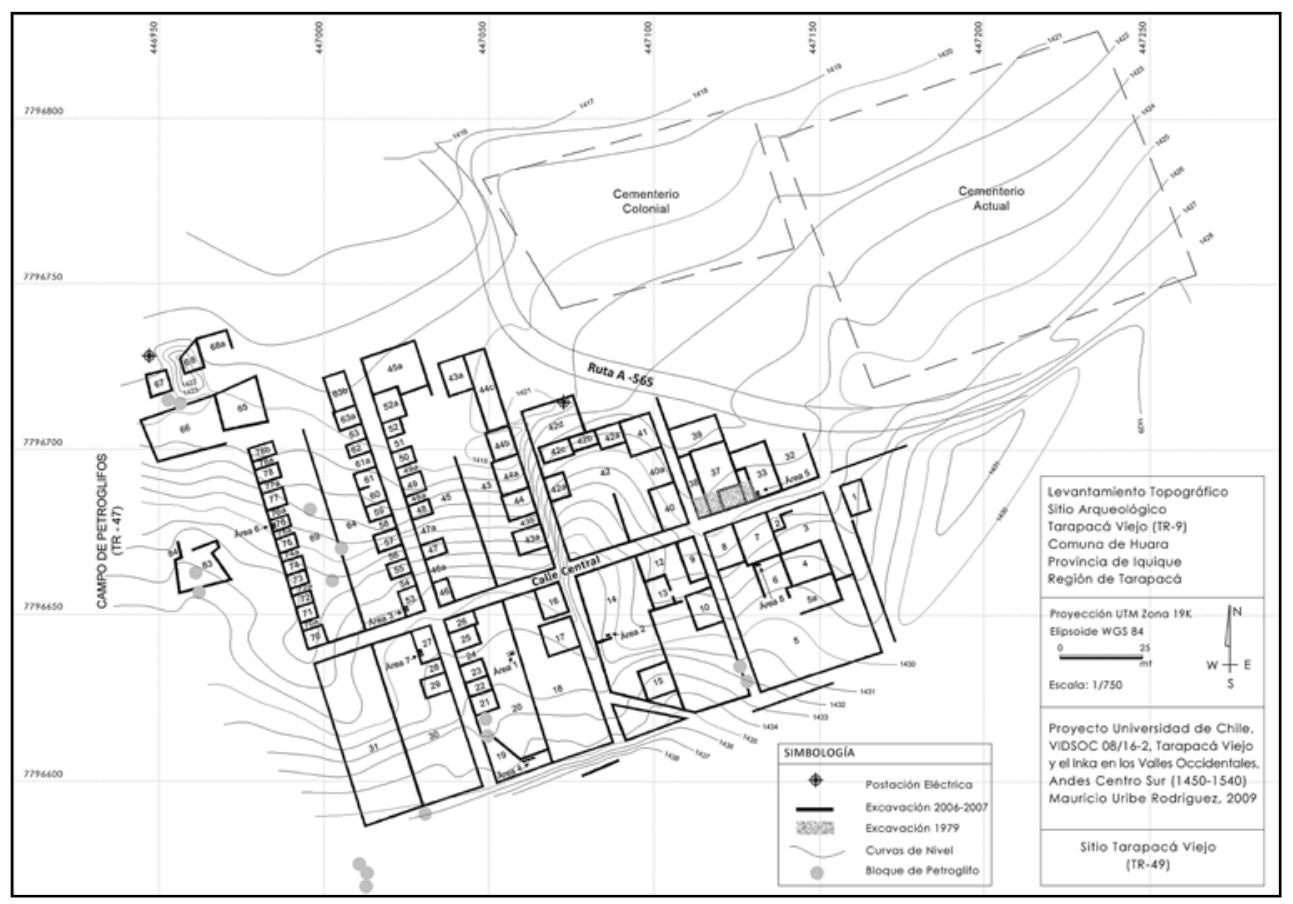

Figura 3. Levantamiento topográfico de Tarapacá Viejo (Fuente: Adán y Urbina 2010).

labores agrícolas, avalando la declaración efectuada por Villegas en 1558 de la residencia de grupos del interior en la costa, otorgando además argumentos de cierta unidad entre el valle longitudinal, la cordillera de la costa y el litoral desértico.

Iquique debió funcionar desde al menos 1540 en adelante como un importante asentamiento costero en el circuito comercial que manejaba Lucas Martínez, encomendero cuyo barco recorría principalmente los puertos de Chule, Quilca, Ilo, Arica y la costa tarapaqueña. Se entiende, por ello, «... la utilidad del barco en el abastecimiento de alimentos y agua a las minas de Tarapacá. Sin las embarcaciones el trabajo de las minas hubiera sido imposible» (Trelles 1991: 54). También se constata la recalada de Pedro de Valdivia en la costa de lo que llama "paraje de Tarapacá» (Rojas-Mix 1991: 128) y en una carta sobre el puerto de Tarapacá, en 1544 «... que es en las provincias del Perú, ochenta leguas [ $\pm 446 \mathrm{~km}$ ] de la ciudad de Arequipa» (Rojas-Mix 1991: 122).

Desde la caleta de Iquique, además, dos o tres huellas permitían a sus habitantes dirigirse a otros puntos de la región. Primero, bordeando la playa al sur, comunicaba con Cavancha, Huaiquique y Bajo Molle hasta Punta Negra; el segundo, serpenteaba el anterior hasta Bajo Molle, para luego ascender a Alto Molle, Pampa del Tamarugal, Mamińa y Pica. El tercero, «... recorría la ceja de unos barrancos directamente hacia el Este para remontar a un alto portezuelo (quebrada de Huantaca) que conducía hasta una serranía próxima donde existían unas faenas mineras incas (Huantajaya); desde allí, atravesando la sierra marítima y la pampa del Tamarugal, seguía hacia la quebrada de Tarapacá» (Advis 1990: 42). Este sendero con dirección al oriente, cruzaba entre el cordón de Huantaca y el cerro Esmeralda (Checura 1977), lugar donde los incas además instalaron la única capacocha conocida en toda la región.

Esta capacocha se ubica a 905 msnm en la cumbre más alta del cerro Esmeralda, entre la quebrada de Huantaca y el cerro Huantajaya, espacio que constituía el núcleo de la mina prehispánica de plata desde el Período Tardío. Este asentamiento de altura de carácter ceremonial fue escenario del sacrificio humano de una joven y una niña, involucrando además «... 104 piezas del ajuar y fina terminación tanto de las cerámicas como de los textiles, los depurados diseños, el símbolo esvástico 


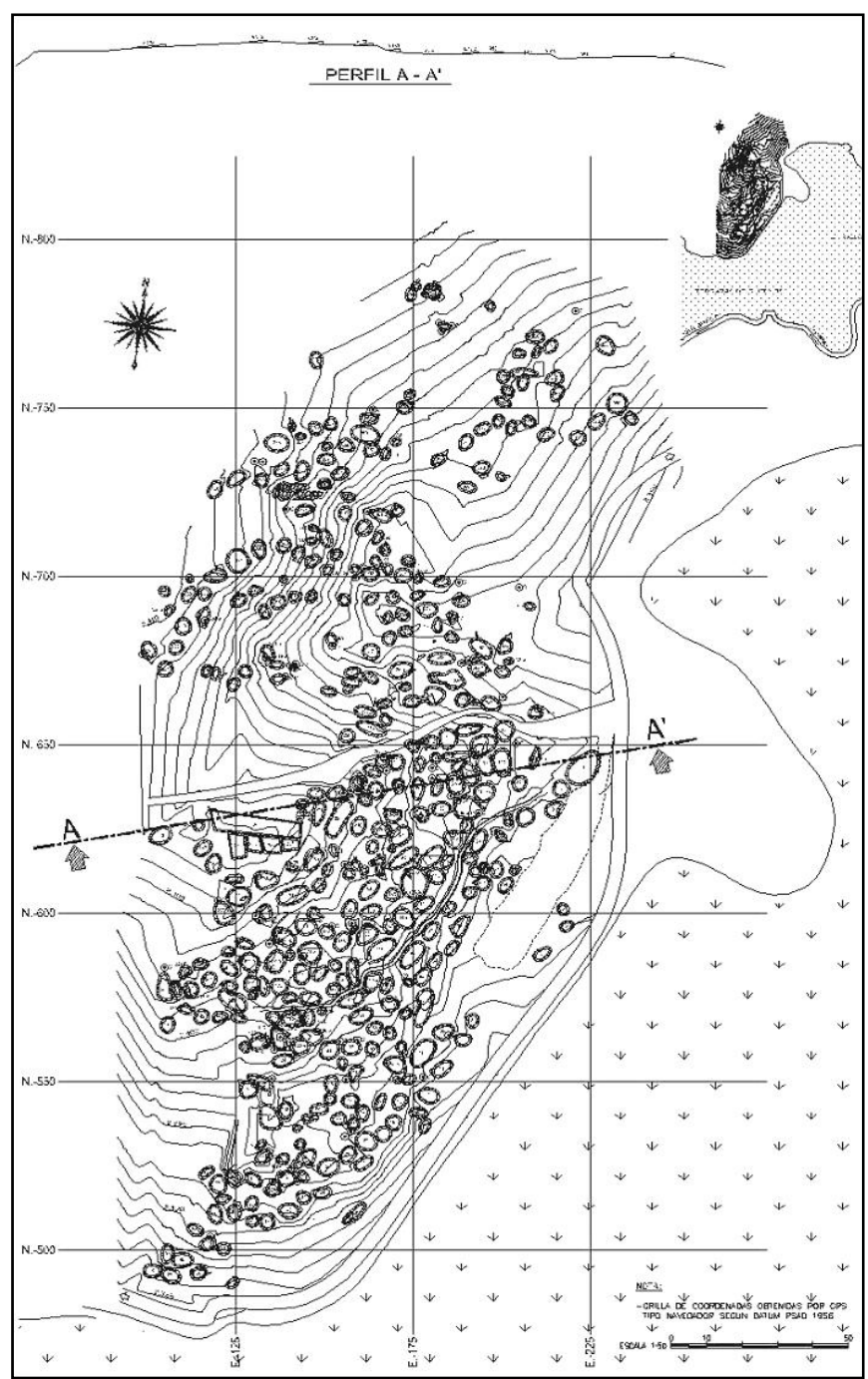

Figura 4. Levantamiento topográfico aldea de Camiña.

de las fajas, los brazaletes de oro y plata, así como las tres conchas de Spondylus princeps princeps, (los que) confirmarían para la momia de Esmeralda su riqueza o privilegiada posición social» (Checura 1977: 140).

Al igual que en las tierras altas (Reinhard y Sanhueza 1982), los incas instalaron este espacio ceremonial de altura o huaca en plena cordillera de la Costa, tutelando el paso que conectaba el puerto de Iquique y el valle de Tarapacá, no obstante, este estaba rodeado de arenales con abundantes papas de plata (Pizarro 1986 [1571]: 189). La asociación entre la capacocha y la explotación incaica de la mina es documentada cuando Hernando Pizarro descubre las minas de Porco «... y tomo aquella mina rica que allí tiene, que de estas minas, y de unas que estaban en Tarapacá, tierra yunga, legua y media de la Mar del Sur, sacaban plata para los reyes de esta tierra" (1986[1571]: 188), donde inclusive «... sacaban plata para el Inca» (Pizarro 1986[1571]: 190, subrayado es nuestro). Se trataba de varias vetas esparcidas en espacio de 10 leguas $( \pm 56 \mathrm{~km})$. Aparte de «las minas del Inca», los mineros indígenas habían comentado la existencia de una veta aún más rica que las ya explotadas por los encomenderos, la cual llamaban «... la veta del Sol» (Pizarro 1986[1571]: 191). 


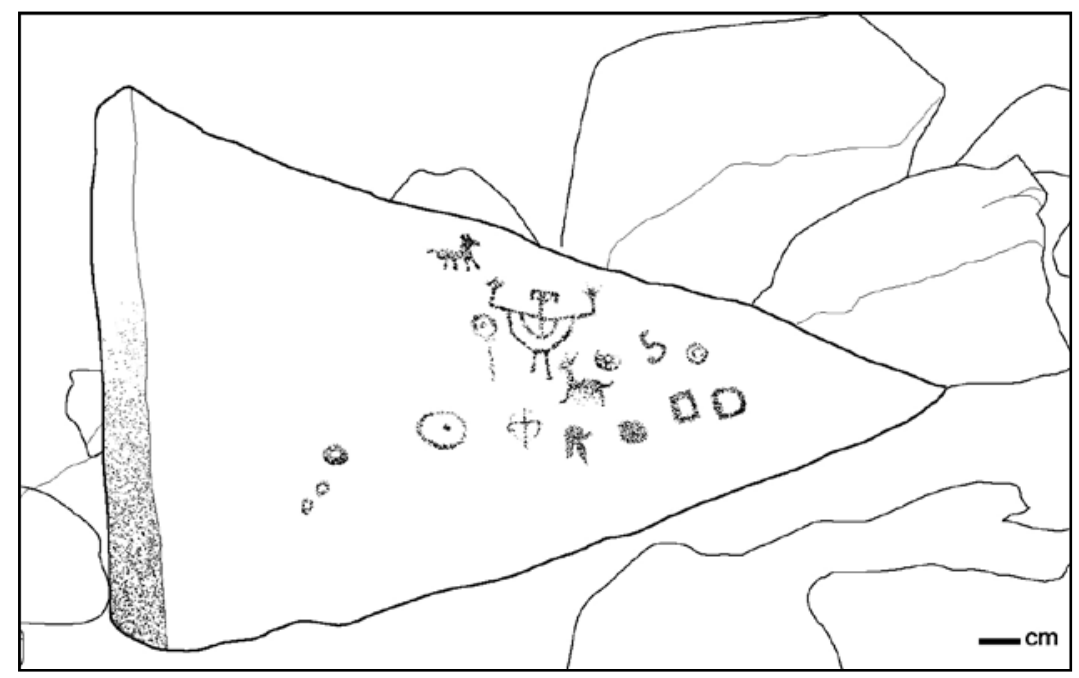

Figura 5. Grabado de figura antropomorfa vistiendo túnica trapezoidal con orillas de urdimbre curvas y "gorro con coletas", aldea Jamajuga (Fuente: Agüero 2007, Vilches y Cabello 2011).

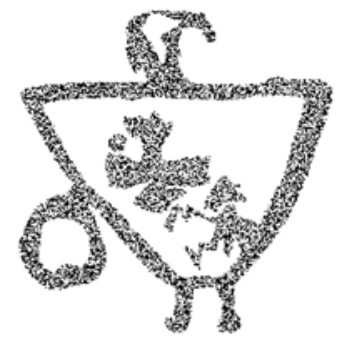

Figura 6. Grabado de figura antropomorfa vistiendo túnica trapezoidal con orillas de urdimbre curvas y "gorro con coletas", aldea Jamajuga (Fuente: Agüero 2007, Vilches y Cabello 2011).

\section{Discusión}

A mediados del siglo XVI Tarapaca constituye una voz indígena registrada por dos tempranos cronistas de la invasión hispana al sur de Cuzco: Gonzalo Fernández de Oviedo y Jerónimo de Vivar. Ambos designan a Tarapaca bajo la figura de una "provincia», la cual, al igual que otras, «... habría correspondido tanto a una percepción de sus condiciones sociopolíticas como a una determinada lectura política de su relación o vinculación con el orbe cristiano español» (Martínez 2011: 113). Según el estudio de Patricio Cisterna, la designación de "provincia» en la narrativa de Bibar refería a aquellos espacios que aún no habían sido conquistados o que estaban sometidos a una situación violenta durante la invasión hispana; funcionaba como término diagramador que permitía ordenar y comprender la «... distribución de los nativos en el espacio» (Cisterna, 1997: 162; 1999: 123).

En el mismo plano, la enunciación «valle» en la crónica de Bibar se usaba descriptivamente para indicar espacios ya civilizados o dominados por los españoles (Cisterna, 1997: 161), aunque cabe suponer dentro de este plano pudiera aludir a territorios/poblaciones ya ocupados/pacificadas por 
los Incas. Sin embargo, respecto de esto último, según define "provincia» el diccionario de lengua castellana de Covarrubias (1987[1611]: 85, citado en Platt et al. 2006: 47), la palabra castellana «...combina dos elementos semánticos en un solo concepto: la idea de extensión geográfica ("tierra estendida"), por una parte; y por otra, la administración de una "región conquistada" por parte de "gobernadores" ("cargos") enviados desde un centro imperial (sea este Roma o Cuzco)». En el sentido que parece ser utilizado en el sur andino, Platt y colaboradores (2006: 49) seńalan que la provincia o suyo sureño del Tawantinsuyo, el Collasuyo, "... estaba bajo el gobierno de un "juez" o "gobernador" [Qhapaq Apu] llamado Apu Chalku Yupanki, hermano de Wayna Qhapaq". En 1535, Apu Chalku junto a Willaq Uma o Villac Umu habrían «allanado el territorio y mandado a la gente del Collao y Charcas a que le sirviesen [a Diego de Almagro]» en su expedición a Chile.

Otra modalidad basada en la sustitución del término "provincia» por el de «nación", notan los autores, la cual dejaría de ser utilizada ya en 1582 (Memorial de Charcas) y otros documentos de fines del siglo XVI (Probanza de los señores de Macha y Sacaca). Aquí se trata de testimonios hispanos e indígenas que utilizan la palabra "nación» para describir o referir a grupos a los que se pertenece, como también a los demás (Platt et al. 2006: 51). En el caso de los Lipes, José Luis Martínez indica con ciertos matices que la mención a la "provincia de los Lipes» aludiría hipotéticamente a una división administrativa incaica: «... cuestión que pareciera entrar en discrepancia, empero, con las múltiples formas de territorialidades dispersas e inter digitación que pareciera caracterizar la ocupación de un espacio por parte de las sociedades andinas [...] se trata de una homologación exigida por una semántica hispana [...] que, entre informaciones poco filtradas de origen cuzqueño y la percepción hispana [...] castellaniza y homologa lo que no necesariamente era una unidad inicial» (Martínez 1995: 297-298).

De esta forma, cuando pasa a ser utilizado ampliamente el término «nación» para los Lipes (v.g. Bernabé Cobo en 1653), se pierden de vista la heterogeneidad de sus componentes (Martínez 1995, en Platt et al. 2006: 51), lo que conlleva una reducción de las categorías o identidades que se perciben en la documentación colonial más temprana. En consecuencia, trátese de referencias anotadas en la documentación colonial asociadas a "provincias», "señoríos» $\mathrm{O}$ «naciones» indígenas, se debe considerar que «... no siempre son homogéneos los grupos sociales que las componen» (Platt et al. 2006: 55).

En las primeras narrativas hispanas, la identificación de sociedades nativas y los etnónimos parecen haber sido subsumidos por la denominación o discursos sobre las tierras y generalmente por sobre las «provincias» más amplias (Martínez 2011: 113). En este caso, se debe poner atención a las "diferencias terminológicas» e implicancias expresadas en la toponimia (geográfica) o como se indican los asentamientos, poblados o «asientos» que emanan de la propia documentación.

En el caso de Tarapaca existen valiosos datos sobre la existencia de relaciones de dependencia entre la autoridad principal del «valle de Tarapaca» y aquellas de Pica y sus anexos, que se asimilan al carácter provincial de otras regiones, especialmente en el lapso en que se produce la intervención del Tawantinsuyo (siglo XV y primera mitad del siglo XVI).

Las evidencias de mayor peso al respecto corresponden al testimonio de Pedro de Ayala en 1563 , quién testifica que «... fue de gran utilidad e provecho para los dichos yndios de Pica juntarse con los de Tarapaca porque es todo un ayllu y lengua y traje e son obedientes a los de Tarapaca y que mandándoles los de Tarapaca sirven a sus amos» (AGI, Justicia, 405B, fs. 134v, en Martínez, 2011, nota 55: 148), y otro testigo, Juan Bautista Ginoves, asegura que «...los yndios de Pica son de la nación de los de Tarapaca» (AGI, Justicia, 405B, fs. 136r, en Martínez 2011, nota 35: 143). La mención a los de Pica «....mandándoles los de Tarapaca sirven a sus amos» y «... son de la nación de los de Tarapaca», debe aludir a cierta subordinación generada por una política de unificación impuesta por el Estado Inca. Esta estrategia provechó y potenció las intensas relaciones históricas, económicas e identidades que ambas poblaciones compartían desde siglos precedentes (s. XIII-XV), tanto en sus lugares de origen como en el litoral desértico.

Con todo, el resultado de esta fusión o integración jerarquizada de ambas «naciones» o parcialidades, develaría la creación efectiva de una jurisdicción indígena; una provincia o wamani incaico 


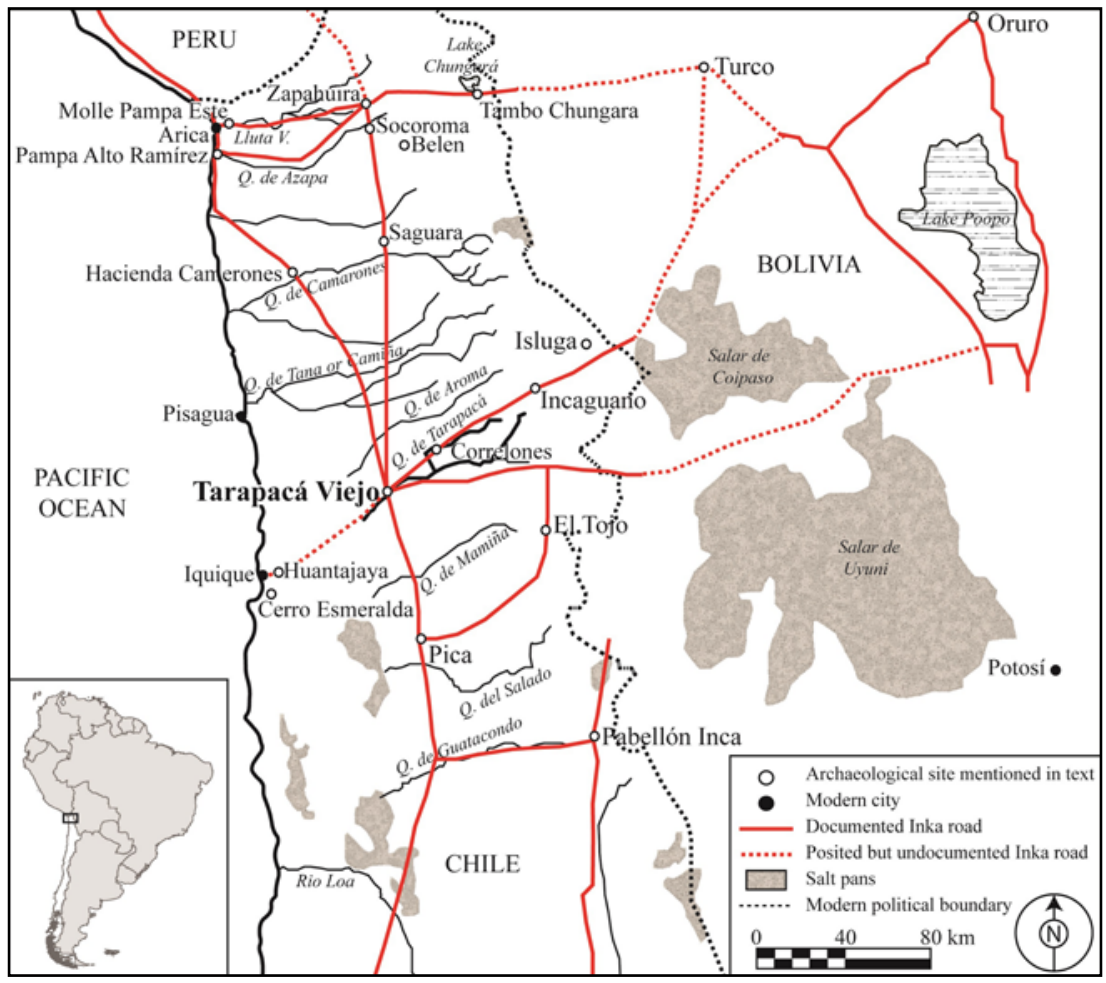

Figura 7. Ubicación de Tarapacá Viejo, valle de Tarapacá, red vial e instalaciones administrativas incaicas en el norte de Chile (Fuente: Zori y Urbina 2014: 213).

unificado bajo el vocablo Tarapaca. Esta provincia habría estado integrada, según testimonios distintos, a los suyos Colla o Conti en distintos momentos de la expansión inca durante el siglo XV y XVI (Tabla 1). Tal estrategia incaica de unificación de señoríos, parcialidades, ayllus o reinos, es similar a la reconocida entre en la unificación del reino Quillacas-Asanaques (Espinoza-Soriano, 1981) y entre las «siete naciones Charcas» en la confederación Charka (Platt et al. 2006: 59-68).

Tal programa político, a su vez reforzado mediante la disposición y mantenimiento de un sistema de alianzas y tensiones estratégicas, traslados poblacionales y de bienes intra/extra regionales focalizados, el cual habrían fomentado y financiado las inversiones de trabajo en remodelación de asentamientos locales, disposición de una red vial oficial convergente al camino principal (cf. Berenguer et al. 2011) — centralizada intra regionalmente en Tarapacá Viejo-, la cual articulaba distintas instalaciones productivas o estratégicas en la región (Fig. 7).

\section{Palabras finales}

Como señalan diversos trabajos efectuados en los Andes del Tawantinsuyo, los repartos hispanos iniciales fueron establecidos en base a la organización que previamente los incas habían dispuesto para jurisdicciones dentro de los suyos denominados provincias o wamani. De acuerdo a esta perspectiva de la historia andina regional, el presente trabajo asume que los wamani anteriores a la invasión hispana correspondían a jurisdicciones de diversa índole, economía, estructura política y tamaño "... más que territorios fijos eran personas, aun cuando los Incas tuvieron aparentemente gran interés por definir los límites territoriales de las provincias conquistadas» (Pärssinen 2002[1993]: 262). 


\begin{tabular}{|c|c|c|c|c|c|c|}
\hline ID & $\begin{array}{c}\text { Autor } \\
\text { [contexto] }\end{array}$ & $\begin{array}{l}\text { Año de referencia } \\
\text { [año publicación] }\end{array}$ & $\begin{array}{l}\text { Inka [funcio- } \\
\text { nario estatal] }\end{array}$ & $\begin{array}{l}\text { Jurisdicción/Suyo } \\
\text { de expansión } \\
\text { [región específica] }\end{array}$ & Datos asociados & $\begin{array}{l}\text { Población/localidades } \\
\text { involucradas }\end{array}$ \\
\hline 1 & $\begin{array}{l}\text { Francisco } \\
\text { Pizarro }\end{array}$ & $\begin{array}{l}\text { 1540, AGI, } \\
\text { Justicia 401, f. } \\
\text { 181v-183v [Barriga } \\
\text { 1955:17-19] }\end{array}$ & [Opo o Apo] & $?$ & $\begin{array}{l}\text { Jurisdición de la ciudad de } \\
\text { Arequipa }\end{array}$ & $\begin{array}{l}\text { Señor de los pueblos } \\
\text { Pachica, Puchurca y } \\
\text { Huaviña }\end{array}$ \\
\hline 2 & $\begin{array}{l}\text { Quipucamayos } \\
\text { [gobiernos y } \\
\text { reyes Inca de- } \\
\text { clarados a Vaca } \\
\text { de Castro] }\end{array}$ & $\begin{array}{l}\text { 1542-1544 [1892: } \\
18]\end{array}$ & Pachacuti & $\begin{array}{l}\text { Toda la costa de } \\
\text { Tarapaca }\end{array}$ & $\begin{array}{l}\text { Vaca de Castro recopila para } \\
\text { Pedro de La Gasca }\end{array}$ & $\begin{array}{l}\text { Coles, Camanchacas, } \\
\text { Uros? }\end{array}$ \\
\hline 3 & $\begin{array}{l}\text { Fernández de } \\
\text { Oviedo }\end{array}$ & 1547 [1901: 250] & $?$ & $\begin{array}{l}\text { La primera del } \\
\text { Collao (Turapaca) }\end{array}$ & $\begin{array}{l}\text {... provincia la cual hayaron } \\
\text { (y estaba) alzada e retirado el } \\
\text { ganado e bastimentos }\end{array}$ & Tarapaca [y Pica] \\
\hline 4 & $\begin{array}{l}\text { Juan Diez de } \\
\text { Betanzos }\end{array}$ & $\begin{array}{l}\text { 1551-1557 [1987: } \\
94 \text { y } 163-167]\end{array}$ & $\begin{array}{l}\text { Pachacuti/ } \\
\text { Topa Inga }\end{array}$ & $\begin{array}{l}\text { Condesuyo( } \\
\text { Arequipa)/ } \\
\text { Atacama }\end{array}$ & $\begin{array}{l}\text { - / Por el camino de los lla- } \\
\text { nos y por la costa de la mar } \\
\text { hasta Arequipa }\end{array}$ & \\
\hline 5 & $\begin{array}{l}\text { Pedro de Cieza } \\
\text { de León }\end{array}$ & 1553 [2005: 436] & Huayna Capac & $\begin{array}{l}\text { pueblos y valles } \\
\text { hacia la mar del } \\
\text { sur }\end{array}$ & $\begin{array}{l}\text { Por otra parte hacia la mar } \\
\text { del Sur envió [Guayna } \\
\text { Capac] más gente con otros } \\
\text { capitanes a que señoreasen } \\
\text { los valles y pueblos que del } \\
\text { todo su padre [Topa Inga] } \\
\text { no pudo conquistar. }\end{array}$ & Términos de Arequipa \\
\hline 6 & $\begin{array}{l}\text { Probanza de los } \\
\text { incas nietos de } \\
\text { conquistadores } \\
\text { [Capac Ayllu] }\end{array}$ & 1569 [1985: 226] & Topa Inga & $\begin{array}{l}\text { Tarapaca pertene- } \\
\text { ce al Collasuyo }\end{array}$ & & \\
\hline 7 & Pedro Pizarro & $\begin{array}{l}1571[1986: 46 \\
\text { y } 220]\end{array}$ & Pachacuti? & $\begin{array}{l}\text { Collasuyo/ De las } \\
\text { provincias de este } \\
\text { reyno }\end{array}$ & $\begin{array}{l}\text { Este YngaViracocha dizen } \\
\text { conquisto y gano y subxeto } \\
\text { asi treinta leguas alrrededor } \\
\text { del Cuzco,donde/poblo este } \\
\text { primer Ynga. Deste Ynga } \\
\text { Viracocha quedo un hijo, } \\
\text { que se llamauaTupa Ynga } \\
\text { Yupangue Pachacuti, y que } \\
\text { este gano cien leguas }\end{array}$ & $\begin{array}{l}\text {... se quentan por } \\
\text { una prouincia; Lima, } \\
\text { Pachacama,Chincha, } \\
\text { Yca, La Nazca, hasta } \\
\text { Hacari es otra; des- } \\
\text { de Hacari hasta Tam- } \\
\text { bo es otra; desdeTam- } \\
\text { bo hasta Pica es otra. } \\
\text { Esto es en la costa } \\
\text { del Mar del Sur. }\end{array}$ \\
\hline 8 & $\begin{array}{l}\text { Pedro } \\
\text { Sarmiento de } \\
\text { Gamboa }\end{array}$ & $\begin{array}{l}1572[1988: 105- \\
106]\end{array}$ & $\begin{array}{l}\text { Pachacuti } \\
\text { [Chuchi } \\
\text { Capac] }\end{array}$ & Collasuyu & $\begin{array}{l}\text { Conquistado en vida de Vi- } \\
\text { racocha (exiliado) }\end{array}$ & $\begin{array}{l}\ldots \text { todos los términos } \\
\text { de Arequipa y la costa } \\
\text { de la mar hacia Ata- } \\
\text { cama }\end{array}$ \\
\hline 9 & $\begin{array}{l}\text { Miguel Cabello } \\
\text { Balboa }\end{array}$ & $\begin{array}{l}1586[1951: 336- \\
337]\end{array}$ & Topa Inga & $\begin{array}{l}\text { Descubrió las mi- } \\
\text { nas de Tarapaca }\end{array}$ & & \\
\hline 10 & $\begin{array}{l}\text { Pedro Mercado } \\
\text { de Peńaloza } \\
\text { [RGI, Jiménez } \\
\text { de la Espada] }\end{array}$ & $\begin{array}{l}\text { 1588-1589 [1965, } \\
\text { vol. I: } 337]\end{array}$ & Topa Inga & $\begin{array}{l}\text { Pacajes } \\
\text { (Collasuyo) }\end{array}$ & & $\begin{array}{l}\text { (a los Pacajes)... les } \\
\text { seńaló tierras de maíz } \\
\text { en la costa de Arica y } \\
\text { Arequipa }\end{array}$ \\
\hline 11 & $\begin{array}{l}\text { I. Garcilazo de } \\
\text { la Vega }\end{array}$ & $\begin{array}{l}1609 \text { [1995, t. I: } \\
311]\end{array}$ & Viracocha & $\begin{array}{l}\text { Hecha la visita de } \\
\text { Cuntisuyo entró a } \\
\text { las provincias del } \\
\text { Collasuyu }\end{array}$ & $\begin{array}{l}\ldots \text { anduvo una por una } \\
\text { visitando los pueblos más } \\
\text { principales }\end{array}$ & $\begin{array}{l}\text { Visitió aquella costa de } \\
\text { la mar hasta Tarapaca }\end{array}$ \\
\hline 12 & $\begin{array}{l}\text { Juan de Santa } \\
\text { Cruz Pachacuti }\end{array}$ & 1613 [1968: 300] & Pachacuti & $\begin{array}{l}\ldots \text { yendo por el } \\
\text { Collao }\end{array}$ & $\begin{array}{l}\text {...topa con los yndios Ccoles } \\
\text { y Camanchacas }\end{array}$ & \\
\hline 13 & Bernabé Cobo & 1653 [1964: 80-81] & Pachacuti & $\begin{array}{l}\text { Provincias marí- } \\
\text { timas }\end{array}$ & & \\
\hline
\end{tabular}

Fuente: Modificado de Urbina 2014, Tabla 21: 327.

Tabla 1. Expansión documentada del Tawantinsuyo a Tarapaca. 
Con todo, el análisis de los testimonios hispanos iniciales, como la presencia del capacocha de cerro Esmeralda y las minas de plata cercanas al puerto de Iquique; el centro administrativo incaico (Tarapacá Viejo o pueblo de Tarapaca) en el mismo valle (valle de Tarapaca-desagüe del valle de Cato), donde se menciona una autoridad Inca del alto rango - como fue el caso del señor Opo (Apu?) - , y no en Pica, brindan sustento a la idea de una articulación político territorial de Tarapaca determinada por su incorporación paulaitna al Tawantinsuyo. Consecuentemente, si tal fuera el caso, se debiera reponer el valor de aquellas inferencias de Zapater (1981: 249, 251 y 253) y Silva (1992-1993: 86-87) respecto de la incorporación parcial de Tarapaca a uno o más suyos inca, dejando abierta la pregunta sobre si la propia región conformaba - y el término Tarapaca denominaba-, una jurisdicción incaica claramente definida al momento de la invasión hispana.

\section{Agradecimientos}

Este trabajo es resultado de los proyectos Fondecyt 1030923, 1071132 y 1130667 y del proyecto VID SOC08/16-2, financiados por el Fondo Nacional de Desarrollo Científico y Tecnológico de Chile y la Vicerrectoría de Investigación de la Universidad de Chile, respectivamente. Parte de los resultados analizados en este artículo forman parte de la tesis de magíster del primer autor, guiada por el doctor Jorge Hidalgo. Por su apoyo y diálogo intelectual a Leonor Adán, Carolina Agüero, José Berenguer, Victoria Castro, José Luis Martínez, Carolina Odone.

\section{Notas}

${ }^{1}$ Se utiliza el término «Tarapacá» para referir a la actual quebrada homónima y a la I Región de Chile. Se utiliza la anotación Tarapaca respecto de usos registrados en la documentación histórica (siglo XV-XVI).

${ }^{2}$ Barriga 1955, t. III: 17-20; Larraín 1975: 275-280; Villalobos 1979: 21-44; Wachtel 2001[1990]: 561-582, Trelles 1991; Pärssinen 2002[1993]: 229-267 y 325-353; Hidalgo 2004[2003, 1987, 1999], cap. 20, 21 y 22: 431-506; Platt et al. 2006: 23-134 y 239-318, Hidalgo 2009: 143-199.

${ }^{3}$ Según comenta Hidalgo: «Es frecuente encontrar en arqueólogos e historiadores de ésta área un uso no crítico de los textos de Cúneo-Vidal (...) es necesario advertir que cuando Cúneo-Vidal cita documentos lo hace frecuentemente con grandes alteraciones de los textos originales, lo que impide su uso serio en investigación» (2004[1997], nota 2: 537).

${ }^{4}$ Este es un tema abierto a nuevas investigaciones. Según Cieza de León, Huaina Capac estando en Charcas envió a parte de su ejército que descendiese por la cordillera hacia el mar del sur y «... señoreasen en los valles y en los pueblos que del todo su padre [Topa Inga] no pudo conquistar» (Cieza 1553 [2005: 436]). Otra versión señala que Pachacuti o Topa Inga conquistaron el Colesuyo y específicamente Arequipa (Rowe 1944: 271-272, en Pärssinen 2002[1993]: 125). Fuentes coloniales publicadas con posterioridad al clásico estudio de Rowe (1946), plantean con cierto nivel de duda que la región de Coles y Camanchacas, entre Ica y Tarapacá, fuera anexada por Pachacuti (Betanzos 1987[1551]: 94 y 163-167; Santa Cruz Pachacuti 1993[1613]: 226, f. 22v; Pärssinen 2002[1993], notas 263 y 265: 127). Según Pärssinen «... Amaro Topa y algunos otros jefes militares conquistaron hasta Chicha, en el Collasuyo, y hasta Arequipa, en el Contisuyo. Sin embargo, no sabemos si la faja costera comprendida entre Ica y Tarapacá fue conquistada en esa época, o más tarde, cuando Topa Inca había tomado ya el comando supremo del estado inca» (Pärssinen 2002[1993]: 128).

5 «Cobertura de la cabeza, o bonete, que remata en punta inclinada hacia atrás» (Diccionario de Autoridades, 1729: 142, foj. 2.). Sitio web: www.rae.es (consultado el 25/12/2011). 


\section{REFERENCIAS}

\section{Adán, L. y S. Urbina}

2010 Arquitectura quebradeña del Complejo Pica-Tarapacá: modos de hacer, opciones de diseño, rasgos significativos y decisiones funcionales, Actas del XVII Congreso Nacional de Arqueologia Chilena, tomo II: 865-876, Valdivia.

Advis, P.

1989 Alcance geográfico del nombre valle de Tarapacá en la temprana colonia, Revista Camanchaca 8: 36-43.

1990 Ique-Ique de los pescadores (La caleta prehispánica), Revista Camanchaca 11:37-44.

1995 La iglesia colonial de San Antonio de Matilla: su origen, su fechado y sus transformaciones, IECTA, Iquique.

2008 El desierto conmovido. Paso de la hueste de Almagro por el norte de Chile, Dirección de Extensión Académica y Cultural, Universidad Arturo Prat, Iquique.

Agüero, C.

2007 Acerca del rol del vestuario en el surgimiento, desarrollo y consolidación del Complejo Pica-Tarapacá (Período Intermedio Tardío), tesis de maestría, Universidad Católica del Norte-Universidad de Tarapacá, Arica/San Pedro de Atacama.

Agüero, C., M. Uribe, P. Ayala y B. Cases

1997 Variabilidad textil durante el Período Intermedio Tardío en el valle de Quillagua: Una aproximación a la etnicidad, Estudios Atacameños 14: 263-290.

Barriga, V.

1933 Los Mercedarios del Perú, vol. 1, Roma.

1952 Memoria para la Historia de Arequipa, tomo IV, Arequipa.

1955 Documentos para la Historia de Arequipa 1535-1580, tomo III, Arequipa.

Betanzos, J. de

1987 Suma y narración de los Incas [transcripción de María del Carmen Martín Rubio], Atlas, Madrid.

[1551]

Berenguer, J., C. Sanhueza e I. Cáceres

2011 Diagonales incaicas, interacción interregional y dominación en el altiplano de Tarapacá, norte de Chile, en: L. Núñez y A. Nielsen (eds.), Ruta, arqueología, historia y etnografía del tráfico sur andino, 247-283, Encuentro Grupo Editor, Córdoba.

Briones, L., L. Núnez y V. Standen

2005 Geoglifos y tráfico prehispánico de caravanas de llamas en el desierto de Atacama (norte de Chile), Chungara 37(2): 195-223. https://doi.org/10.4067/s0717-73562005000200007

Chacón, S. y J. Hidalgo

1983 La Isla del Alacrán. Antecedentes prehispánicos, su papel en la defensa colonial de Arica y análisis de sus ruinas, Chungara 13: 53-66.

Checura, J.

1977 Funebria incaica en el cerro Esmeralda (Iquique, I Región), Estudios Atacameños 5: 125-141.

Cieza de León, P.

2005 Crónica del Perú. El señorio de los Incas, Fundación Biblioteca Ayacucho, Caracas.

[1553]

Cisterna, P.

1997 Escritura y poder en el siglo XVI: la cuestión del indígena en la crónica de Gerónimo de Vivar, tesis maestría, Departamento de Ciencias Históricas, Universidad de Chile, Santiago.

1999 El enunciado provincia en el ámbito de la conquista y colonización hispana, Revista de Humanidades 5: 97-124.

Cúneo-Vidal, R.

2004 Historia de los antiguos cacicazgos hereditarios del Sur del Perú, Obras completas, tomo 1, vol. 2. Lima.

[1977]

D'Altroy, T.

2002 The Incas, Blackwell Publishers, Massachusetts/Oxford.

Espinoza-Soriano, W.

1981 El reino aymara de Quillaca-Asanaque, siglos XV y XVI, Revista del Museo Nacional 45:175-274. 
Fernández de Oviedo, G.

1901 Historiad General y Natural de las Indias Isla y tierra firme del mar océano, Colección de Historiadores

[1557] de Chile, tomo XXVII, cap. VI: 249-254.

Hidalgo, J.

1986 Indian Society in Arica, Tarapacá and Atacama1750-1793 and its response to the rebellion of Tupac Amaru, tesis de doctorado, Universidad de Londres, Londres.

2004 Historia andina en Chile, Editorial Universitaria, Santiago.

2009 Los pescadores de la costa norte de Chile y su relación con los agricultores, en: J. Topic (ed.), La arqueologia y la etnohistoria: Un encuentro andino, 143-199. Instituto de Estudios Peruanos/Instituto de Estudios Andinos, Lima.

Hyslop, J.

1984 The Inca road system, Academic Press, Orlando.

1990 Inca settlement Ppanning, University of Texas Press, Austin.

Larraín, $\mathrm{H}$.

1975 La población indígena de Tarapacá (Norte de Chile) entre 1538 a 1581, Revista Norte Grande, vol. I, 3-4: 269-300.

Lockhart, J.

1968 Spanish Perú 1532-1560. A social history, The University of Wisconsin Press, Madison.

Lozano de Machuca, J.

1992 Carta del factor de Potosí Juan Lozano de Machuca al virrey del Perú Don Martín Enríquez en que da

[1581] cuenta de cosas que aquella villa y de las minas de los Lipez, Estudios Atacameños 10: 30-31.

Martínez, J. L.

1995 Papeles distantes, palabras quebradas. Las informaciones sobre Lipes en el siglo XVI, en: A. M. Presta (ed.), Espacio, etnias, frontera. Atenuaciones politicas en el sur del Tawantinsuyu, siglos XV-XVIII, 285-317, Ediciones ASUR, Sucre.

2011 Gente de la tierra de guerra. Los lipes en las tradiciones andinas y el imaginario colonial, Pontificia Universidad Católica del Perú/DIBAM, Lima/Santiago.

Medina, J. T.

1888 Colección de documentos inéditos para la historia de Chile, Primera serie, Imprenta Elzeviriana, Santiago.

$-1902$

Meza, N.

1950 Algunos documentos relativos a Pedro de Valdivia, Revista Chilena de Historia y Geografía 115: 16-39.

Museo Chileno de Arte Precolombino (MChAP)

2015 Gorros del desierto de Atacama, Museo Chileno de Arte Precolombino, Santiago.

Morris, C. y A. Covey

2003 La plaza central de Huánuco Pampa: espacio y transformación, Boletín de Arqueología PUCP 7: 133-149.

Núñez, L.

1978 L'evolution millenaire d'une valle: peuplement et resources a Tarapacá, en: N. Watchtel y J. Murra (eds.), Annales. economies, societes, civilizations, 906-920. París.

1979 Emergencia y desintegración de la sociedad Tarapaqueña: riqueza y pobreza en una quebrada del Norte Chileno, Atenea 439: 163-213.

1984 Tráfico de complementariedad de recursos entre las tierras altas y el Pacífico en el área Centro Sur Andina, tesis de doctorado, tomo II, Departamento de Antropología Cultural, Universidad de Tokio, Japón.

2006 Asentamientos formativos complejos en el centro-sur andino: cuando la periferia se constituye en núcleo, Boletín de Arqueología PUCP 10: 321-356.

Núñez, P.

1984 La antigua aldea de San Lorenzo de Tarapacá, norte de Chile, Chungara 13: 53-66.

Odone, C.

1994 La territorialidad indígena y española en Tarapacá colonial (Siglos XVI-XVIII): Una proposición, tesis de licenciatura, Instituto de Historia, Pontificia Universidad Católica de Chile, Santiago.

Pärssinen, $\mathrm{M}$.

2002 Tawantinsuyu. El estado Inca y su Organización Política, Pontificia Universidad Católica del Perú/Embajada

[1993] de Finlandia/Instituto Francés de Estudios Andinos, Lima. 
2002 Confederaciones interprovinciales y grandes señores interétnicos en el Tawantinsuyo, Boletín de Arqueología PUCP 6: 23-42.

Pizarro, P.

1986 Relación del descubrimiento y conquista de los reinos del Perú, Pontificia Universidad del Perú, Lima.

[1571]

Platt, T., T. Bouysse-Cassagne y O. Harris

2006 Qaraqara-Charka. Mallku, Inka y rey en la provincia de Charcas (Siglos XV-XVII). Historia Antropológica de una Confederación Aymara, Instituto Francés de Estudios Andinos/ Plural Editores/University of St. Andrews/University of London, Inter American Foundation, Fundación Cultural del Banco Central de Bolivia, La Paz.

Real Academia de la Lengua Española

1726- Diccionario de Autoridades. http://www.rae.es/rae.html (consultado en 15/10/2011).

1729

Reinhard, J. y J. Sanhueza

1982 Expedición arqueológica al altiplano de Tarapacá y sus cumbres, Revista CODECI 2(2): 19-42.

Rojas-Mix, M.

1991 Cartas de Don Pedro de Valdivia que tratan del descubrimiento y conquista de la Nueva Extremadura, Editorial Andrés Bello/Editorial Lumen S.A., Barcelona.

\section{Rostworowski, M.}

1986 La región del Colesuyo, Chungara 16-17: 127-136.

1988 Estructuras andinas de poder, Instituto de Estudios Peruanos, Lima.

Rowe, J.

1946 Inca culture at the time of the Spanish Conquest, en: J. Steward (ed.), Handbook of South American Indians, vol. II, 183-330, Bureau of American Ethnology, Bulletin 143, Washington, D.C.

Sanhueza, C.

2008 Territorios, prácticas rituales y demarcación del espacio en Tarapacá en el siglo XVI, Boletín del Museo Chileno de Arte Precolombino 13(2): 57-75.

Santa Cruz Pachacuti Yamqui Salcamayhua, J. de

1993 Relación de Antigüedades deste Reyno del Piru, Centro de Estudios Bartolomé de Las Casas, Cusco.

[1613]

Silva, $O$.

1992- Reflexiones acerca del dominio incaico en Tarapacá (Chile), Diálogo Andino 11-12: 77-94.

1993

Trelles, E.

1991 Lucas Martínez de Vegazo: Funcionamiento de una encomienda peruana inicial, Fondo Editorial Pontificia Universidad Católica del Perú, Lima.

Urbina, $S$.

2009 El altiplano de Tarapacá en tiempos del Tawantinsuyo. Arquitectura de las instalaciones incaicas (s. XVXVI d.C.), memoria para optar al Título profesional de Arqueólogo, Departamento de Antropología, Universidad de Chile, Santiago.

2014 Asentamientos, poblaciones y autoridades de Tarapaca, siglos XV Y XVI (ca. 1400-1572), tesis de mestría, Departamento de Ciencias Histórica, Universidad de Chile, Santiago.

2015 Tarapaca antes del período Colonial: la incorporación al Tawantinsuyo y la invasión hispana (s. XV-XVI), Actas del XIX Congreso Nacional de Arqueología Chilena, 393-400, Arica.

Urbina, S., L. Adán, C. Moragas, S. Olmos y R. Ajata

2011 Arquitectura y asentamientos formativos en la costa desértica de Tarapacá, norte de Chile, Estudios Atacameños 41: 21-34. https://doi.org/10.4067/s0718-10432011000100005

Uribe, $M$.

2006 Arqueología de Pica-Tarapacá (norte de Chile): Reflexiones acerca de la complejidad y desigualdad social en los Andes Centro Sur (1000-1450 DC), Estudios Atacameños 31: 91-114. https://doi.org/10.4067/ s0718-10432006000100007

2009 El Periodo Formativo de Tarapacá y su cerámica: avances sobre complejidad social en la costa del Norte Grande de Chile (900 a. C.-800 d. C.), Estudios Atacameños 37, 5-27. 
Uribe, M. y S. Urbina

2010 Tarapacá Viejo: Historia ocupacional de un centro incaico en los Valles Occidentales del norte de Chile, Actas del XVII Congreso Nacional de Arqueología Argentina, tomo III: 1321-1326, Mendoza.

Uribe, Mauricio, Simón Urbina y Colleen Zori

2012 La presencia del Inca y la incorporación de Tarapacá al Tawantinsuyo (Norte Grande de Chile), Actas del XVIII Congreso Nacional de Arqueología Chilena, 217-228, Valparaíso.

Vilches, F. y G. Cabello

2011 Variaciones sobre un mismo tema: el arte rupestre asociado al complejo Pica-Tarapacá, norte de Chile, Chungara 43(1): 37-52. https://doi.org/10.4067/s0717-73562011000100003

Villalobos, S.

1979 La economía de un desierto. Tarapacá durante la Colonia, Ediciones Nueva Universidad, Santiago de Chile.

Vivar, G.

1979 Crónica y relación copiosa y verdadera de los Reinos de Chile, Colección de escritores coloniales de Chile

[1558] 13, Editorial Universitaria, Santiago.

Wachtel, N.

2001 El regreso de los antepasados. Los indios Urus de Bolivia, del siglo XX al XVI, Fondo de Cultura Económica, \{1990] México.

Zapater, $\mathrm{H}$.

1981 Los Incas y la conquista de Chile, Historia 16: 249-268.

Zori, C.

2011 Metals for the Inka: Late prehispanic transformations in the Tarapaca Valley, northern Chile, University of California, Los Angeles.

Zori, C. y S. Urbina

2014 Architecture and empire at Late Prehispanic Tarapacá Viejo, northern Chile, Chungara 46(2): 211-232. 